\title{
Baseline quality of life as a prognostic survival tool in patients receiving sunitinib for metastatic renal cell carcinoma
}

\author{
D Cella*,1, AG Bushmakin ${ }^{2}$, JC Cappelleri ${ }^{2}$, C Charbonneau ${ }^{3}$, MD Michaelson ${ }^{4}$ and RJ Motzer ${ }^{5}$ \\ 'Department of Medical Social Sciences, Northwestern University Feinberg School of Medicine, Chicago, IL, USA; ${ }^{2}$ Global Research and Development, \\ Pfizer Oncology, New London, CT, USA; ${ }^{3}$ Global Outcomes Research, Pfizer Oncology, New York, NY, USA; ${ }^{4}$ Massachusetts General Hospital Cancer \\ Center, Boston, MA, USA; ${ }^{5}$ Memorial Sloan-Kettering Cancer Center, New York, NY, USA
}

BACKGROUND: In a randomized phase III trial of sunitinib vs interferon-alfa (IFN- $\alpha$ ) in metastatic renal cell carcinoma (mRCC), better baseline quality of life (QoL) was predictive of longer survival. Using this dataset, we have developed a novel prognostic tool that establishes a relationship between baseline QoL scores and median survival time.

METHODS: Baseline QoL was assessed using the FACT-Kidney Symptom Index-I5 item (FKSI-I5), its disease-related symptoms (FKSI-DRS) subscale, and the Functional Assessment of Cancer Therapy-General (FACT-G) scale. Weibull models estimated median progression-free survival (mPFS) and overall survival ( $\mathrm{MOS}$ ) as a function of baseline QoL.

RESULTS: Longer PFS and OS were associated with higher baseline FKSI- I5, FKSI-DRS, and FACT-G scores $(P<0.05)$, and baseline FKSI- I 5 score was the best predictor of survival. For example, for a baseline FKSI- 15 score of 60, the predicted mPFS was 67.9 weeks, and predicted mOS was 240.6 weeks. The magnitude of benefit was greater with sunitinib vs IFN- $\alpha$ for a given baseline QoL score. CONCLUSION: This novel tool indicates that baseline FKSI- I 5 scores were linked to mPFS and mOS in a clear and interpretable way. The results support evaluation of patient-reported QoL symptoms at baseline as a prognostic indicator of survival in clinical research and practice.

British Journal of Cancer (2012) I 06, 646-650. doi:10.1038/bjc.20 I I.589 www.bjcancer.com

Published online 12 January 2012

(c) 2012 Cancer Research UK

Keywords: metastatic renal cell carcinoma; quality of life; prognostic tool; sunitinib; survival; Weibull model

Historically, metastatic renal cell carcinoma (mRCC) has been a difficult disease to manage, because of its resistance to chemotherapy and radiotherapy. The development of targeted therapies (such as small molecule kinase inhibitors and vascular endothelial growth factor (VEGF) antibodies) has led to more promising clinical outcomes (Sun et al, 2010). Sunitinib malate (SUTENT; Pfizer Inc., New York, NY, USA) is an oral multitargeted inhibitor of VEGF receptor, platelet-derived growth factor receptor, and several other kinases that is approved for the treatment of advanced RCC as well as imatinib-resistant/intolerant gastrointestinal stromal tumour (Chow and Eckhardt, 2007). In a randomized, multicenter, phase III trial (ClinicalTrials.gov: NCT00083889; sponsor: Pfizer), sunitinib showed superior progression-free survival (PFS; the primary endpoint) over interferon-alfa (IFN- $\alpha$ ) as first-line mRCC therapy (11 vs 5 months $(P<0.001))$; in addition, median overall survival (mOS) with sunitinib was $>2$ years (26.4 vs 21.8 months with IFN- $\alpha(P=0.051))$ (Motzer et al, 2009).

Various clinical factors - such as haematological and inflammatory markers, site and number of metastases, performance status, tumour stage, time between diagnosis and treatment, and previous surgery - have been investigated to determine their ability to predict survival in patients with mRCC (Motzer et al, 2002, 2004; Bensalah et al, 2006; Suppiah et al, 2006; Choueiri

* Correspondence: Professor D Cella; E-mail: d-cella@northwestern.edu Received 25 August 2011; revised I December 2011; accepted 16 December 20 I I; published online 12 January 2012 et al, 2007; Kwak et al, 2007; Patil et al, 2011). Some of these factors have been used to categorize patients into risk groups to aid clinical trial design and the tailoring of treatment strategies to optimize outcomes. However, few studies have evaluated baseline quality of life (QoL) as a predictor of survival.

Using interim data from the sunitinib phase III trial mentioned above, we previously showed that higher baseline QoL scores were associated with improved PFS (Cella et al, 2009). Using final data from the sunitinib phase III trial, we have now developed a novel prognostic tool that converts baseline QoL scores into median duration of PFS and OS in patients treated with sunitinib.

\section{PATIENTS AND METHODS}

\section{Patients and study design}

Full details have been described previously (Motzer et al, 2007, 2009).

This phase III study population comprised 750 patients $\geqslant 18$ years with histologically confirmed mRCC with a component of clear-cell histology. Key eligibility criteria included: no previous systemic therapy for RCC; measurable disease, Eastern Cooperative Oncology Group performance status 0 or 1 ; and adequate hepatic, renal, and cardiac function. All patients provided written informed consent.

Patients were randomly assigned in a $1: 1$ ratio to receive either sunitinib or IFN- $\alpha$ in repeated 6 -week cycles. Sunitinib was 
administered orally at $50 \mathrm{mg}$ day for 4 weeks, followed by 2 weeks off treatment (Schedule 4/2). IFN- $\alpha$ was administered as a subcutaneous injection on three non-consecutive days per week, starting at 3 million units (MU) for the first week, $6 \mathrm{MU}$ for the second week, and $9 \mathrm{MU}$ thereafter.

The study was approved by the institutional review board or ethics committee at participating centres and was conducted in accordance with provisions of the Declaration of Helsinki and Good Clinical Practice guidelines.

\section{Assessments}

As described previously (Motzer et al, 2007, 2009), tumour imaging was performed at screening, on day 28 of cycles 1-4 and even cycles thereafter, whenever progression was suspected or to confirm response, and at the end of treatment. Tumour response was assessed by investigators according to Response Evaluation Criteria in Solid Tumours (Therasse et al, 2000). PFS was defined as the time from randomization to first documentation of objective tumour progression or death due to any cause. Patients were followed off-study every 2 months for survival.

QoL was measured at baseline using all available data from the following patient-reported questionnaires: the Functional Assessment of Cancer Therapy-Kidney Symptom Index (FKSI)15 item (Figure 1) (Cella et al, 2006), which measures symptoms related to kidney cancer such as 'I feel fatigued', 'I have been short of breath', 'I am bothered by fevers', 'I have had blood in my urine', and rates the severity of each item; its nine-item diseaserelated symptoms (FKSI-DRS) subscale (Cella et al, 2007); the Functional Assessment of Cancer Therapy-General (FACT-G) (Cella et al, 1993); and its four subscales (physical well-being, social/family well-being, emotional well-being, and functional well-being). Higher scores indicated better outcomes (better QoL or fewer symptoms).

\section{Statistical methods and analysis}

Weibull (parametric) models were used to establish a relationship between baseline QoL score and median survival time (using SAS LIFEREG (Kleinbaum and Klein, 2005; SAS Institute Inc., 2008)). These models were applied separately to the sunitinib and IFN- $\alpha$ arms, and OS and PFS were analysed as separate outcomes. In order to estimate $95 \%$ confidence intervals (CIs) for the between-treatment differences in estimated median survival times, 50000 bootstrap simulations were performed. Akaike's information criterion (AIC) (Akaike, 1974), a measure of goodness of fit, where lower values indicate a better fit, was used to identify the QoL instrument that provided the best predictive power for median survival time. Additionally, a Kaplan-Meier estimation method (Kaplan and Meier, 1958) (non-parametric approach) was used to perform sensitivity analyses by forming, for each QoL measure, three tertile groups on QoL scores of approximately equal size (the lowest, highest, and in-between scores), and estimating for each group the median OS time and median PFS time, as well as by examining the entire Kaplan-Meier curve for each group across the QoL scores (using SAS PROC LIFETEST (SAS Institute Inc., 2008)).

\section{RESULTS}

\section{Baseline characteristics}

As previously reported (Cella et al, 2008, 2009, 2010), there were no significant between-treatment differences in the baseline characteristics of patients - including baseline QoL scores, which were in the moderate range (Table 1 ).

For example, baseline FKSI-DRS scores (mean \pm s.d.) were $29.74 \pm 5.24$ and $29.55 \pm 5.03$ for patients in the sunitinib and IFN- $\alpha$ arms, respectively (FKSI-DRS scores can range from 0 (most severe symptoms) to 36 (no symptoms)).

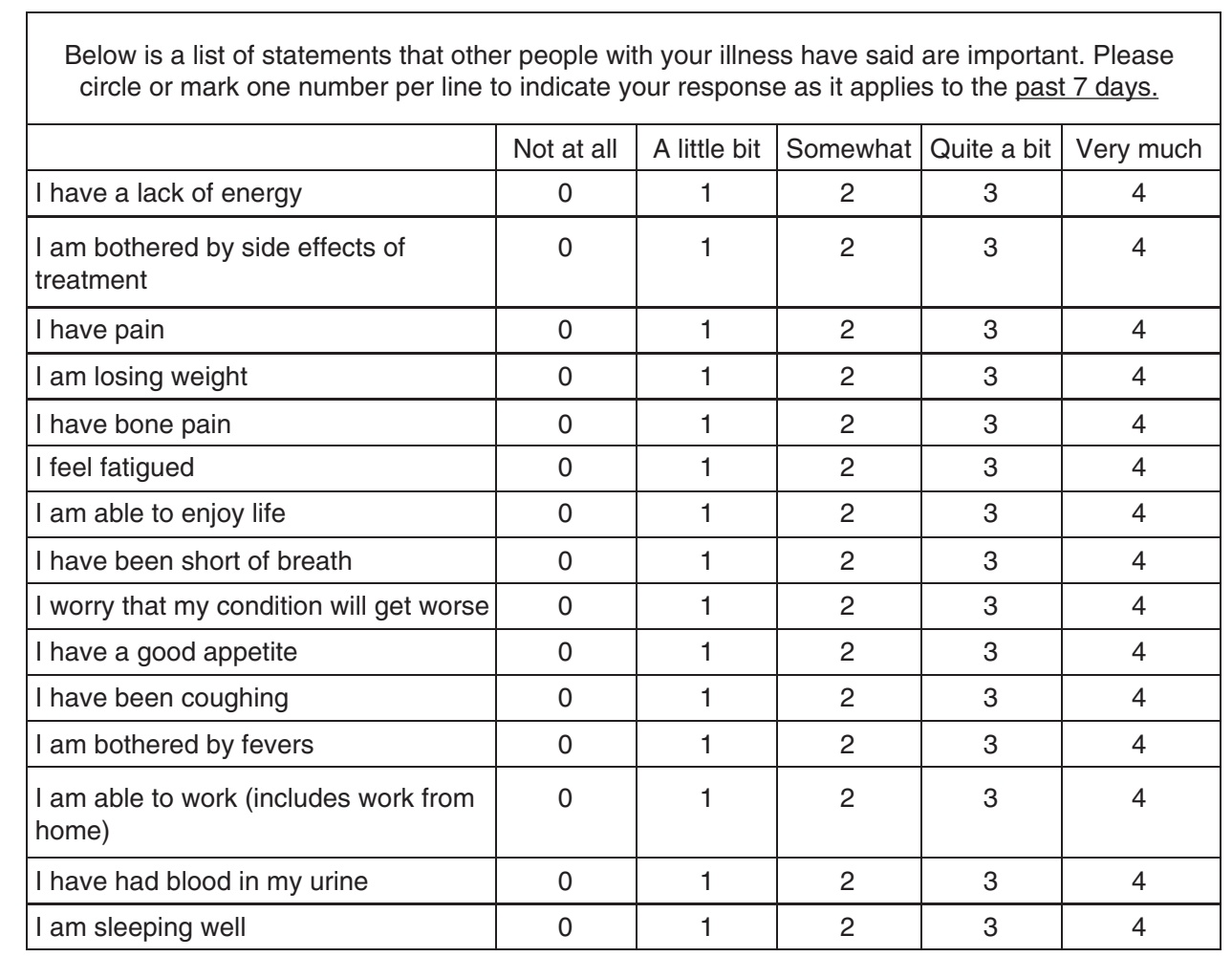

(C) 2007. Reprinted with permission, FACIT.org.

Figure I The Functional Assessment of Cancer Therapy-Kidney Symptom Index (FKSI)-I5 item long form questionnaire 2007. Reprinted with permission, FACIT.org. 
Table I Baseline patient demographics and clinical characteristics (Cella et al, 2008, 2009)

\begin{tabular}{|c|c|c|}
\hline & Sunitinib $(n=375)$ & IFN- $\alpha(n=375)$ \\
\hline Median age (years) & 61 & 60 \\
\hline \multicolumn{3}{|l|}{ Sex, \% } \\
\hline Male & 71 & 72 \\
\hline Female & 29 & 28 \\
\hline \multicolumn{3}{|l|}{ ECOG PS, $\%^{\mathrm{a}}$} \\
\hline 0 & 62 & 61 \\
\hline I & 38 & 38 \\
\hline 2 & 0 & 1 \\
\hline \multicolumn{3}{|l|}{ MSKCC risk factors, \% } \\
\hline 0 & 38 & 34 \\
\hline $1-2$ & 56 & 59 \\
\hline$\geqslant 3$ & 6 & 7 \\
\hline Previous nephrectomy, \% & 90 & 89 \\
\hline Previous radiotherapy, \% & 14 & 14 \\
\hline \multicolumn{3}{|l|}{ No. of disease sites, $\%$} \\
\hline 1 & 14 & 19 \\
\hline 2 & 29 & 30 \\
\hline$\geqslant 3$ & 57 & 51 \\
\hline \multicolumn{3}{|l|}{ Site of metastasis, \% } \\
\hline Lung & 78 & 79 \\
\hline Liver & 26 & 24 \\
\hline Bone & 30 & 30 \\
\hline Lymph nodes & 58 & 53 \\
\hline \multicolumn{3}{|l|}{ QoL scores (mean \pm s.d.) } \\
\hline FKSI- I5 & $46.45 \pm 8.46$ & $46.10 \pm 8.70$ \\
\hline FKSI-DRS & $29.74 \pm 5.24$ & $29.55 \pm 5.03$ \\
\hline FACT-G & $82.30 \pm 15.20$ & $81.25 \pm 16.04$ \\
\hline
\end{tabular}

Abbreviations: ECOG PS = Eastern Cooperative Oncology Group performance status; FACT-G = Functional Assessment of Cancer Therapy-General; FKSI15 = Functional Assessment of Cancer Therapy-Kidney Symptom Index- 15 item; FKSI-DRS = Functional Assessment of Cancer Therapy-Kidney Symptom IndexDisease-Related Symptoms; IFN- $\alpha=$ interferon-alfa; $\quad M S K C C=$ Memorial SloanKettering Cancer Center; $n=$ number of subjects; $Q \circ=$ quality of life;

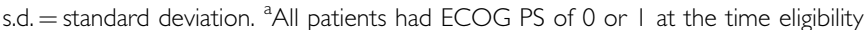
was determined; four patients in the IFN- $\alpha$ group had an ECOG PS of 2 on the day of starting study treatment.

\section{Predictive value of baseline QoL}

All available data for the FACT-Kidney Symptom Index-15 item (FKSI-15), FKSI-DRS, and FACT-G at baseline were used in the analyses. Longer median PFS and OS were associated with higher (more favourable) baseline FKSI-15, FKSI-DRS, and FACT-G scores (each $P<0.05$ from the Weibull model) in patients on sunitinib or IFN- $\alpha$.

Based on it having the lowest AIC value overall (range for OS models: from 792.3 to 826.0 ; range for PFS models: from 841.2 to 851.3), the baseline FKSI-15 score was the best QoL instrument for predicting PFS and OS.

Figure 2 and Table 2 show predicted median PFS and median OS as a function of baseline FKSI-15 scores in patients on sunitinib. Table 3 lists the estimated parameters of the models for PFS and OS. For baseline FKSI-15 scores of 30 and 60 (where $0=$ most symptoms and $60=$ no symptoms), median PFS was predicted to be 29.6 and 67.9 weeks, respectively, and median OS was predicted to be 49.3 and 240.6 weeks, respectively. Therefore, relative to patients with lower baseline (less favourable) FKSI-15 scores, patients with higher FKSI-15 scores at baseline (i.e., those who had fewest cancer-related symptoms) experienced longer median PFS and median OS, which increased exponentially after a baseline FKSI-15 score of around 30.
A

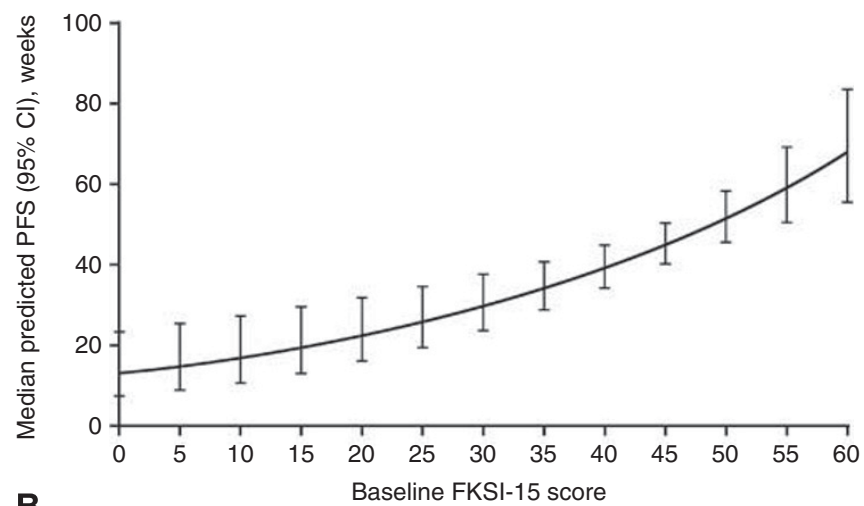

B

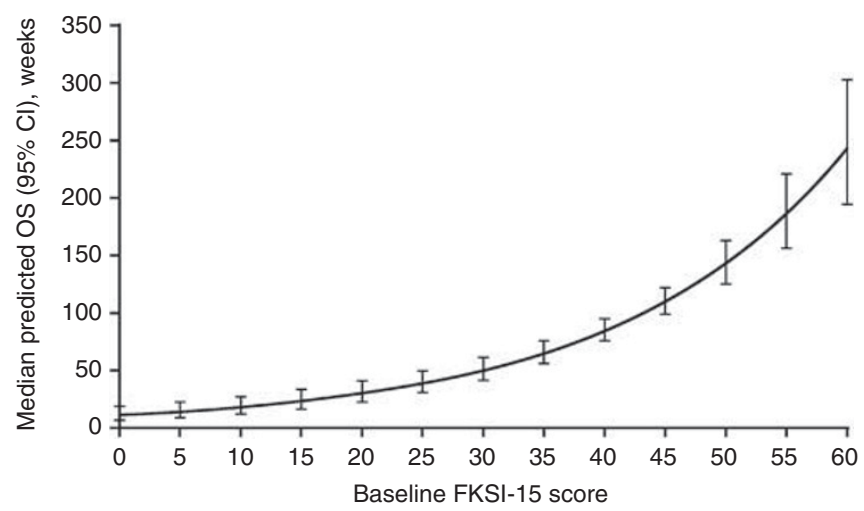

Figure 2 Predicted median (A) PFS and (B) OS as a function of baseline FKSI-I5 scores in patients on sunitinib. Abbreviations: $\mathrm{Cl}=$ confidence interval; FKSI-I5=Functional Assessment of Cancer Therapy-Kidney Symptom Index-15 item; OS = overall survival; PFS = progression-free survival.

Table 2 Predicted median PFS and OS by baseline FKSI-15 score in patients on sunitinib

\begin{tabular}{llc}
\hline $\begin{array}{l}\text { Baseline } \\
\text { FKSI-I I score }\end{array}$ & $\begin{array}{l}\text { Predicted PFS } \\
\mathbf{( 9 5 \%} \mathbf{C I}) \mathbf{n}=\mathbf{3 7 2}\end{array}$ & $\begin{array}{l}\text { Predicted OS } \\
\mathbf{( 9 5 \%} \mathbf{C I}) \mathbf{n}=\mathbf{3 7 2}\end{array}$ \\
\hline 0 & $12.94(7.19,23.30)$ & $10.10(5.89,17.34)$ \\
5 & $14.86(8.78,25.16)$ & $13.16(8.14,21.28)$ \\
10 & $17.06(10.71,27.18)$ & $17.14(\mid 1.25,26.11)$ \\
15 & $19.59(\mid 3.06,29.38)$ & $22.32(15.53,32.07)$ \\
20 & $22.49(15.92,31.78)$ & $29.06(21.43,39.42)$ \\
25 & $25.81(19.37,34.41)$ & $37.85(29.53,48.53)$ \\
30 & $29.64(23.53,37.34)$ & $49.30(40.56,59.91)$ \\
35 & $34.03(28.46,40.69)$ & $64.20(55.40,74.40)$ \\
40 & $39.07(34.12,44.75)$ & $83.62(74.64,93.67)$ \\
45 & $44.86(40.08,50.20)$ & $108.90(97.83,121.21)$ \\
50 & $51.50(45.60,58.16)$ & $141.82(\mid 24.25,161.88)$ \\
55 & $59.13(50.53,69.20)$ & $184.70(154.91,220.23)$ \\
60 & $67.89(55.24,83.43)$ & $240.55(191.57,302.05)$ \\
\hline
\end{tabular}

Abbreviations: $\mathrm{Cl}=$ confidence interval; FKSI- $15=$ Functional Assessment of Cancer Therapy - Kidney Symptom Index - 15 item; OS = overall survival; PFS = progressionfree survival. There were no observed scores below 20 points on the FKSI-15. As such, prediction estimates were extrapolations in this range and may not be as reliable as other prediction estimates where data were observed.

\section{Between-treatment comparisons}

A comparison of the between-treatment (sunitinib vs IFN- $\alpha$ ) percentage differences in predicted median PFS and (separately) median OS as a function of baseline FKSI-15 scores indicated that, for a given baseline QoL score, the magnitude of benefit was 
Table 3 Parameter estimates for PFS and OS models $(n=372)$

\begin{tabular}{lcc}
\hline Parameter & Estimate & $\mathbf{9 5 \%} \mathbf{~ C l}$ \\
\hline Intercept & & \\
PFS & 2.86 & $2.28,3.44$ \\
OS & 2.58 & $2.05,3.11$ \\
& & \\
Score & & \\
$\quad$ PFS & 0.03 & $0.02,0.04$ \\
OS & 0.05 & $0.04,0.07$ \\
Scale & & \\
PFS & 0.82 & $0.73,0.91$ \\
OS & 0.74 & $0.65,0.84$ \\
Weibull shape & & \\
PFS & 1.23 & $1.10,1.37$ \\
OS & 1.36 & $1.20,1.54$ \\
\hline
\end{tabular}

Abbreviations: $\mathrm{Cl}=$ confidence interval; $\mathrm{OS}=$ overall survival; $\mathrm{PFS}=$ progression-free survival.
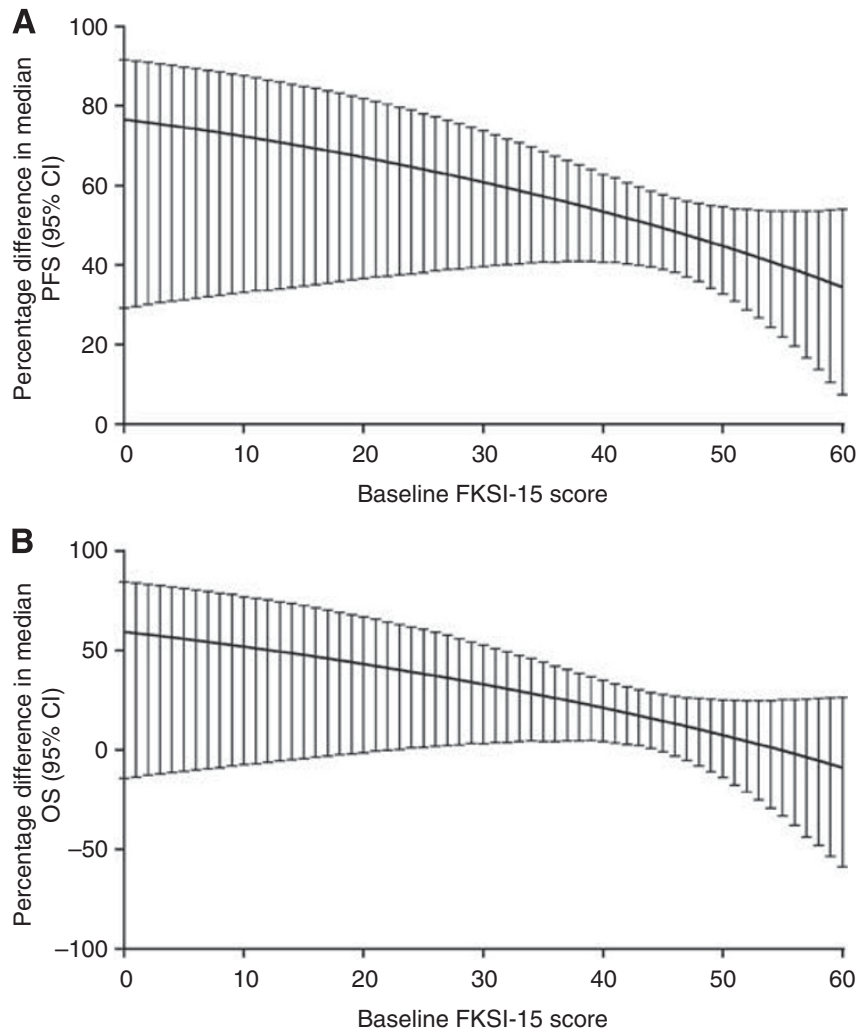

Figure 3 Between-treatment (sunitinib vs IFN- $\alpha$ ) percentage differences in predicted median (A) PFS and (B) OS as a function of baseline FKSI- I5 scores. Abbreviations: PFS = progression-free survival; $O S=$ overall survival: $\mathrm{Cl}=$ confidence interval; FKSI- $15=$ Functional Assessment of Cancer Therapy-Kidney Symptom Index- 15 item. Note: a two-sided 95\% Cl for the between-treatment difference that does not contain 0 indicates that the difference in the treatment arms was statistically significant.

greater with sunitinib relative to IFN- $\alpha$ (Figure 3). For the same FKSI-15 score, predicted median PFS was always significantly better in the sunitinib arm relative to the IFN $-\alpha$ arm; predicted median OS trended in favour of sunitinib, but not all the betweentreatment differences were significant.

In addition, the survival benefit of sunitinib relative to IFN- $\alpha$ increased with worsening baseline kidney symptoms (lower FKSI-15 scores); Figure $3 \mathrm{~A}$ shows that a patient on sunitinib with a baseline FKSI-15 score in the range 0-20, for example, had a predicted median PFS that was $\sim 70 \%$ longer than that of a patient on IFN- $\alpha$ with the same baseline FKSI-15 score range; whereas, a patient on sunitinib with a baseline FKSI-15 score in the range $50-60$ had a predicted median PFS that was $\sim 40 \%$ longer than that of the equivalent IFN- $\alpha$ patient. All between-treatment percentage differences in predicted median PFS were statistically significant, based on the two-sided 95\% CIs not containing 0 .

Similarly, there was an $\sim 50 \%$ difference in predicted median OS, favouring sunitinib, in patients with baseline FKSI-15 scores in the range $0-22$, although this difference was not statistically significant (Figure 3B). A patient on sunitinib with a baseline FKSI-15 score in the range $23-44$ had a predicted median OS that was $\sim 30 \%$ longer than that of the equivalent IFN- $\alpha$ patient, and statistically significant (Figure 3B). In patients with baseline FKSI15 scores in the range 45-60, between-treatment percentage differences in predicted median OS were small and not statistically significant (Figure 3B).

\section{Sensitivity analyses}

Sensitivity analyses using Kaplan-Meier (non-parametric) estimation supported the results of the parametric modelling. Differences between the two models in terms of predicted median PFS, as well as median OS, were less than $10 \%$ (data not shown).

\section{DISCUSSION}

The randomized phase III trial of first-line sunitinib in mRCC patients showed superior PFS $v s$ IFN $-\alpha(11$ vs 5 months $(P<0.001))$, and median OS of more than 2 years (26.4 vs 21.8 months with IFN- $\alpha(P=0.051)$ (Motzer et al, 2009)). In a previous publication, further analysis of interim data from this trial showed that baseline QoL (including FKSI-15 scores) was a significant predictor of PFS, even after other prognostic variables (e.g., treatment and key demographic and clinical variables) were added to the model (Cella et al, 2009). In this full (final) dataset, QoL continues to be a predictor of PFS and also OS, even after other prognostic variables were added to the model (age, sex, baseline Eastern Cooperative Oncology Group performance status, number of Memorial SloanKettering Cancer Center risk factors, prior nephrectomy and radiotherapy, number of metastases, and sites of metastases).

In the present report, we describe a novel prognostic tool that establishes a relationship between baseline QoL and both median PFS and OS. The question posed in this research is whether - and to what extent - baseline FKSI-15 scores predict median survival, not which of several prognostic factors best predict median survival. As such, this effort extends beyond prior research. The current study adds originality by predicting median PFS and OS times and their 95\% CI, from the baseline scores. As such, the analyses take into account the inherent variability in median PFS or OS for any given score.

Our results revealed a robust relationship between baseline FKSI-15 scores and median survival time. Increased median PFS and OS were associated with higher (better or more favourable; fewer symptoms) baseline FKSI-15 scores in patients on sunitinib or IFN- $\alpha$. These findings are consistent with our earlier analysis (Cella et al, 2009) and with a phase III trial of second-line sorafenib in mRCC patients, which showed that the total baseline FKSI score was predictive for OS $(P<0.0001)$ and that favourable baseline QoL scores were associated with subsequent improvement in survival outcomes (Bukowski et al, 2007). That the 15-item FKSI questionnaire was the best predictor of PFS and OS likely relates to the fact that this instrument is specific to symptoms of kidney cancer (unlike the FACT-G that provides a more general assessment of QoL) (Cella et al, 2006). 
Our findings based on parametric modelling are considered to be robust as they were supported by results of the sensitivity analyses with the Kaplan-Meier (non-parametric) estimation. Although the Weibull parametric model used in this analysis is not a novel analytic approach in itself, our application of the model to associate a given baseline score with a median survival time is original. Similarly, our application of the Kaplan-Meier estimation method for performing sensitivity analyses is novel in this setting.

The present results also demonstrated that median PFS and OS were superior for sunitinib relative to IFN- $\alpha$ for a given patient QoL score. For the same FKSI-15 score, the predicted PFS was always significantly better in the sunitinib arm relative to the IFN- $\alpha$ arm, while the predicted OS trended in favor of sunitinib but the between-treatment differences were not always significant.

These findings reaffirm the importance of evaluating patientreported QoL. For the clinician, knowledge of baseline FKSI-15 scores provides additional guidance on likely outcomes for individual patients, whereas for the patient, it is encouraging to know that by reporting their symptoms they are contributing valuable information that will help to inform decisions on their overall management.

In summary, this novel tool indicates that baseline FKSI-15 scores were linked to median PFS and OS in a clear and interpretable way in these mRCC patients treated with sunitinib or IFN- $\alpha$. The results support the evaluation of patient-reported QoL symptoms at baseline as a prognostic indicator of survival times in clinical trials and practice. Although the modelling approach used in this analysis is applicable to other clinical trials (Trask et al, 2011), the findings reported here only pertain to the study population and treatments investigated in the present trial.

\section{ACKNOWLEDGEMENTS}

We would like to thank all of the participating patients and their families, as well as the investigators, research nurses, study coordinators, and operations staff. This study was sponsored by Pfizer. Medical writing support was provided by Rachel Mason at ACUMED (Tytherington, UK) and was funded by Pfizer.

\section{REFERENCES}

Akaike H (1974) A new look at the statistical model identification. IEEE Transactions on Automatic Control 19: 716-723

Bensalah K, Leray E, Fergelot P, Rioux-Leclercq N, Tostain J, Guillé F, Patard JJ (2006) Prognostic value of thrombocytosis in renal cell carcinoma. J Urol 175: 859-863

Bukowski R, Cella D, Gondek K, Escudier B, Sorafenib TARGETs Clinical Trial Group (2007) Effects of sorafenib on symptoms and quality of life: results from a large randomized placebo-controlled study in renal cancer. Am J Clin Oncol 30: 220-227

Cella D, Cappelleri JC, Bushmakin A, Charbonneau C, Li JZ, Kim ST, Chen I, Michaelson MD, Motzer RJ (2009) Quality of life predicts progression-free survival in patients with metastatic renal cell carcinoma treated with sunitinib $v s$ interferon alfa. J Oncol Pract 5: $66-70$

Cella D, Li JZ, Cappelleri JC, Bushmakin A, Charbonneau C, Kim ST, Chen I, Motzer RJ (2008) Quality of life in patients with metastatic renal cell carcinoma treated with sunitinib or interferon-alfa: results from a phase III randomized trial. J Clin Oncol 26: 3763-3769

Cella D, Michaelson MD, Bushmakin AG, Cappelleri JC, Charbonneau C, Kim ST, Li JZ, Motzer RJ (2010) Health-related quality of life in patients with metastatic renal cell carcinoma treated with sunitinib $v s$ interferonalpha in a phase III trial: final results and geographic analysis. $\mathrm{Br} J$ Cancer 102: 658-664

Cella D, Yount S, Brucker PS, Du H, Bukowski R, Vogelzang N, Bro WP (2007) Development and validation of a scale to measure disease-related symptoms of kidney cancer. Value Health 10: 285-293

Cella D, Yount S, Du H, Dhanda R, Gondek K, Langefeld K, George J, Bro WP, Kelly C, Bukowski R (2006) Development and validation of the Functional Assessment of Cancer Therapy-Kidney Symptom Index (FKSI). J Support Oncol 4: 191-199

Cella DF, Tulsky DS, Gray G, Sarafian B, Linn E, Bonomi A, Silberman M, Yellen SB, Winicour P, Brannon J (1993) The functional assessment of cancer therapy scale: development and validation of the general measure. J Clin Oncol 11: 570-579

Choueiri TK, Garcia JA, Elson P, Khasawneh M, Usman S, Golshayan AR, Baz RC, Wood L, Rini BI, Bukowski RM (2007) Clinical factors associated with outcome in patients with metastatic clear-cell renal cell carcinoma treated with vascular endothelial growth factor-targeted therapy. Cancer 110: $543-550$

Chow LQ, Eckhardt SG (2007) Sunitinib: from rational design to clinical efficacy. J Clin Oncol 25: 884-896

Kaplan EL, Meier P (1958) Nonparametric estimation from incomplete observations. J Am Stat Assoc 53: 457-481
Kleinbaum DG, Klein M (2005) Survival Analysis: A Self-Learning Text, 2nd edn. Springer Science + Business Media, Inc.: New York, NY

Kwak C, Park YH, Jeong CW, Jeong H, Lee SE, Ku JH (2007) Characteristics of metastasis as a prognostic factor for immunotherapy in metastatic renal cell carcinoma. Tumori 93: 68-74

Motzer RJ, Bacik J, Murphy BA, Russo P, Mazumdar M (2002) Interferonalfa as a comparative treatment for clinical trials of new therapies against advanced renal cell carcinoma. J Clin Oncol 20: 289-296

Motzer RJ, Bacik J, Schwartz LH, Reuter V, Russo P, Marion S, Mazumdar M (2004) Prognostic factors for survival in previously treated patients with metastatic renal cell carcinoma. I Clin Oncol 22: 454-463

Motzer RJ, Hutson TE, Tomczak P, Michaelson MD, Bukowski RM, Oudard S, Negrier S, Szczylik C, Pili R, Bjarnason GA, Garcia-del-Muro X, Sosman JA, Solska E, Wilding G, Thompson JA, Kim ST, Chen I, Huang X, Figlin RA (2009) Overall survival and updated results for sunitinib compared with interferon alfa in patients with metastatic renal cell carcinoma. J Clin Oncol 27: 3584-3590

Motzer RJ, Hutson TE, Tomczak P, Michaelson MD, Bukowski RM, Rixe O, Oudard S, Negrier S, Szczylik C, Kim ST, Chen I, Bycott PW, Baum CM, Figlin RA (2007) Sunitinib $v s$ interferon alfa in metastatic renal-cell carcinoma. N Engl J Med 356: 115-124

Patil S, Figlin RA, Hutson TE, Michaelson MD, Négrier S, Kim ST, Huang X, Motzer RJ (2011) Prognostic factors for progression-free and overall survival with sunitinib-targeted therapy and with cytokine as first-line therapy in patients with metastatic renal cell carcinoma. Ann Oncol 22: 295-300 SAS Institute Inc. (2008). SAS/STA ${ }^{\mathbb{B}} 9.2$ User's Guide. SAS Institute Inc.: Cary, NC

Sun M, Lughezzani G, Perrotte P, Karakiewicz PI (2010) Treatment of metastatic renal cell carcinoma. Nat Rev Urol 7: 327-338

Suppiah R, Shaheen PE, Elson P, Misbah SA, Wood L, Motzer RJ, Negrier S, Andresen SW, Bukowski RM (2006) Thrombocytosis as a prognostic factor for survival in patients with metastatic renal cell carcinoma. Cancer 107: $1793-1800$

Therasse P, Arbuck SG, Eisenhauer EA, Wanders J, Kaplan RS, Rubinstein L, Verweij J, Van Glabbeke M, van Oosterom AT, Christian MC, Gwyther SG (2000) New guidelines to evaluate the response to treatment in solid tumors. European Organization for Research and Treatment of Cancer, National Cancer Institute of the United States, National Cancer Institute of Canada. J Natl Cancer Inst 92: 205-216

Trask PC, Bushmakin AG, Cappelleri JC, Tarazi J, Rosbrook B, Bycott P, Kim S, Stadler WM, Rini B (2011) Baseline patient-reported kidney cancerspecific symptoms as an indicator for median survival in sorafenib-refractory metastatic renal cell carcinoma. J Cancer Survivorship 5: 255-262

This work is published under the standard license to publish agreement. After 12 months the work will become freely available and the license terms will switch to a Creative Commons Attribution-NonCommercial-Share Alike 3.0 Unported License. 